ORIGINAL ARTICLE

\title{
MUC4 is increased in high grade intraepithelial neoplasia in Barrett's oesophagus and is associated with a proapoptotic Bax to $\mathrm{BCl}-2$ ratio
}

\author{
D A Bax, J Haringsma, A W C Einerhand, H van Dekken, P Blok, P D Siersema, E J Kuipers, \\ J G Kusters
}

J Clin Pathol 2004;57:1267-1272. doi: 10.1136/icp.2004.017020

See end of article for authors' affiliations

.....................

Correspondence to: Dr J G Kusters, Erasmus MC, University Medical Centre Rotterdam, Department of Gastroenterology and Hepatology, Room L-459, Dr. Molewaterplein 40, 3015 GD Rotterdam, The Netherlands; i.g.kusters@ erasmusmc.nl

Accepted for publication 17 May 2004
Background: Patients with Barrett's oesophagus (BO) are at risk of oesophageal adenocarcinoma. Because the pattern of mucosal mucins changes during neoplastic progression, it may serve as a marker of intraepithelial neoplasia.

Aims: To determine the expression pattern of mucins in neoplastic BO epithelium (high grade dysplasia) and correlate it with the expression of apoptosis markers Bax and $\mathrm{BCl}-2$.

Methods: Thirty seven patients with $\mathrm{BO}$ were studied: 16 without intraepithelial neoplasia, six with high grade intraepithelial neoplasia (HGN), and 15 with infiltrating adenocarcinoma. Biopsies were obtained from squamous epithelium, Barrett's epithelium, and (when present) foci of suspected HGN or adenocarcinoma. MUC1-4, MUC5AC, MUC5B, MUC6, Bax, and Bcl-2 mRNA were determined by semiquantitative RT-PCR. MUC2, MUC5AC, and MUC6 protein was determined by immunoblotting. Results: Mucin expression varied between neoplastic progression stages in BO. Mucin mRNA levels were low in squamous epithelium, except for MUC4, and were at least four times higher in BO and HGN $(p<0.001)$, but less so in adenocarcinoma. MUC4 expression was significantly lower in BO than in normal squamous epithelium, whereas in $\mathrm{HGN}$ and adenocarcinoma, levels were significantly higher than in $B O(p=0.037)$. The Bax:Bcl-2 ratio was increased in HGN compared with BO $(p=0.04)$. MUC2, MUC5AC, and MUC6 protein values correlated with mRNA data.

Conclusions: Mucin expression varies during the development of oesophageal adenocarcinoma in BO. MUC4 could serve as a tumour marker in this process. In contrast to animal studies, upregulation of MUC4 in HGN is associated with increased apoptosis, suggesting that MUC4 plays a minor role in apoptosis regulation in $\mathrm{BO}$.
B arrett's oesophagus (BO) is a premalignant condition in which the normal squamous epithelium of the lower oesophagus is replaced by specialised columnar epithelium. Gastro-oesophageal reflux is believed to play an important role in the aetiology of $\mathrm{BO}^{1{ }^{12}}$ Adenocarcinoma (ADC) is thought to develop in BO in a stepwise manner, via low grade intraepithelial neoplasia and high grade intraepithelial neoplasia (HGN). ${ }^{3}$ ADC has a poor prognosis, because metastasis occurs early and symptoms present late in the course of the disease. The overall five year survival is only $10-15 \%{ }^{4}$

\begin{abstract}
"Markers that indicate the presence of high grade intraepithelial neoplasia could be helpful in the identification of patients at risk of malignant transformation"
\end{abstract}

Early detection of malignant progression is the key factor for improving the outcome of oesophageal ADC. Current guidelines recommend endoscopic surveillance to detect intraepithelial neoplasia (often referred to as dysplasia) and to diagnose carcinoma at an early treatable stage. ${ }^{5}$ However, the efficacy of endoscopic surveillance is thwarted by several factors. ${ }^{6}$ Sampling error can occur in endoscopic random biopsy sampling. ${ }^{7}$ In addition, a correct pathological diagnosis of intraepithelial neoplasia is difficult and focal neoplastic changes can easily be missed in small biopsy samples. This is reflected by a considerable interobserver and intraobserver variability among pathologists in the interpretation of epithelial changes in $\mathrm{BO}^{8}$
The use of molecular markers in addition to normal endoscopical and histological evaluation could significantly enhance the detection of neoplasia in $\mathrm{BO}$, both in vitro and in vivo. In particular, markers that indicate the presence of HGN could be helpful in the identification of patients at risk of malignant transformation.

Mucins are large glycoproteins that are the main components of the gel-like mucous layer on the surface of the intestine. This layer serves to protect the mucosa from mechanical damage. Each type of mucosa has a unique pattern of mucin expression, and this pattern changes during neoplastic progression. Therefore, mucins are putative molecular markers for the development of adenocarcinoma in BO. Currently, more than 10 MUC genes have been reported, the best characterised being MUC1-4, MUC5AC, MUC5B, and MUC6. Of these, only MUCl and MUC4 are expressed in the normal squamous lining of the oesophagus, ${ }^{9}$ whereas BO predominantly expresses MUC2, and to a lesser extent MUC5AC and MUC6. ${ }^{10-12}$

In addition to protection against mechanical damage, membrane bound mucins MUCl and MUC4 have also been reported to be involved in oncogenic pathways. MUCl can bind to $\beta$ catenin, thereby altering its ability to bind to E-cadherin, which leads to decreased cell-cell adhesion and

Abbreviations: $A D C$, adenocarcinoma; $A P$, alkaline phosphatase; $B O$, Barrett's oesophagus; HGN, high grade intraepithelial neoplasia; PCR, polymerase chain reaction; RT, reverse transcription 
Table 1 Polymerase chain reaction primers

\begin{tabular}{lll}
\hline Amplified gene & Forward primer & Reverse primer \\
\hline MUC1 & 5'TGCATCAGGCTCAGCTTCTA3' & 5'ACGTCGTGGACATTGATGGT3' \\
MUC2 & 5'CAGGATGGCGCCTCTGCTA3' & 5'ÁTGCTGCTCCAAGCTGAGGT3' \\
MUC3 & 5'CCAGCCAGGATGTGAACAG3' & 5'GCAGTCGATGGCGTTGTC3' \\
MUC4 & 5'CTGTCACATCGCGCACGTCT3' \\
MUC5B & 5'TCAACGCCTCGGTGGCATAC3' & 5'GCCTGGAAGACTTGGCCATT3' \\
MUC5AC & 5'TGACGGCACCTCTIACACC3' & 5'TCTGTGGCGGTATATGGTG3' \\
MUC6 & 5'CCGGAGGTGAACATGGAC 3' & 5'CGCCTCCTCTGTGGCTCAT3' \\
Bax & 5'GCAGGAGGAGATCACGTCA3' & 5'GCCACGTGGGCGTCCCAAAGT3' \\
Bcl-2 & 5'GGCCCACCAGCTCTGAGCAGA3' & 5'ÁGGCACCCAGGGTGATGCAA3' \\
$\beta$ actin & 5'GTGGAGGAGCTCTCAGGGA3' & 5'AGTCATAGTCCGCCTAGAAG3' \\
\hline
\end{tabular}

uncontrolled proliferation. ${ }^{13}{ }^{14}$ MUC4, a mucin that is upregulated in several tumour types, acts as a ligand for the receptor tyrosine kinase, Erb-B2, thereby regulating the p2 $7^{\text {kip }}$ cell cycle inhibitor. ${ }^{15}$ MUC4 also inhibits apoptosis in a xenotransplanted melanoma model in nude mice. ${ }^{16}$

The aim of our study was to evaluate the expression patterns of MUC1-4, MUC5AC, MUC5B, and MUC6 in high grade intraepithelial neoplasia and adenocarcinomas in $\mathrm{BO}$, and to determine the association with the apoptosis markers Bax and Bcl-2.

\section{METHODS}

\section{Patients}

In total, 37 patients with BO were studied. Sixteen patients had BO without intraepithelial neoplasia, six patients had BO with high grade intraepithelial neoplasia, and 15 had an infiltrating adenocarcinoma. Patients were evaluated by standard oesophagoscopy and high magnification chromendoscopy. Biopsies were obtained from the squamous epithelium, Barrett's epithelium, and (when present) from foci of suspected high grade intraepithelial neoplasia or adenocarcinoma. Two expert gastrointestinal pathologists independently evaluated haematoxylin and eosin stained sections for the presence of $\mathrm{BO}$, grade of intraepithelial neoplasia, and ADC. All patients diagnosed with high grade intraepithelial neoplasia routinely underwent endomucosal resection. Endomucosal resection specimens were independently analysed by two pathologists to ensure that there were no indications for the presence of an (infiltrating) adenocarcinoma. Ten patients with adenocarcinoma were treated surgically and five patients received palliative treatment. All adenocarcinomas had infiltrated into the submucosa and three patients had local lymph node metastases. Eight tumours were well differentiated and seven were poorly differentiated. Our study was approved by the ethical committee of the Erasmus MC Rotterdam, The Netherlands, and informed consent was obtained before endoscopy.

\section{RNA and protein isolation from biopsies}

Biopsies were snap frozen in liquid nitrogen. Total RNA was isolated using TRIzol reagent (Invitrogen, Groningen, The Netherlands), according to the manufacturer's instructions. The remaining chromosomal DNA was removed with the RNA free DNA kit (Zymo, Orange, California, USA). Total RNA concentrations were estimated by RNA electrophoresis on an agarose gel and band intensity was compared with that of a marker band with a known concentration. From the same biopsy specimen, a protein fraction was isolated according to the manufacturer's instructions and denatured in $1 \%$ sodium dodecyl sulfate. Protein concentrations were determined with the BCA protein assay kit (Pierce, Rockford, Illinois, USA).

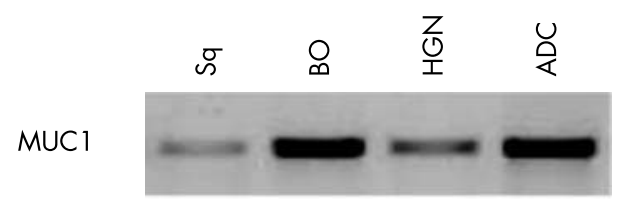

MUC2

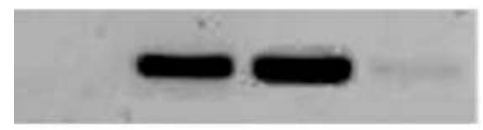

MUC3

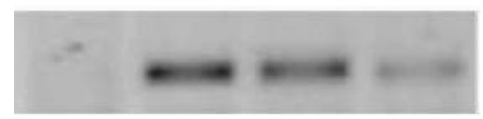

MUC4

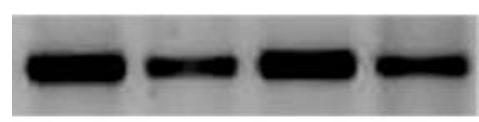

MUC5AC

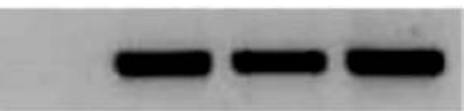

MUC5B

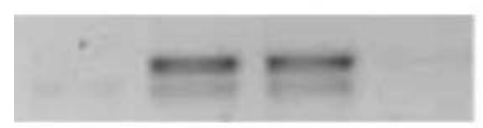

MUC6

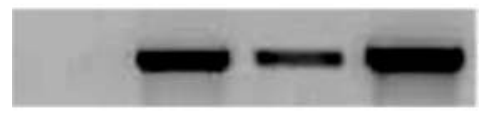

$\beta$ actin

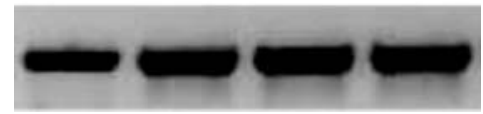

Figure 1 Representative examples of reverse transcriptase polymerase chain reaction (RT-PCR) results. mRNA of MUC1, MUC2, MUC3, MUC4, MUC5AC, MUC5B, and MUC6 in squamous epithelium (Sq), Barrett's oesophagus ( $B O)$, and adenocarcinoma (ADC). mRNA was isolated from biopsy samples of a patient with $B O$ containing $H G N$ and $A D C$. $\beta$ Actin was used as a control for RNA input. PCR products were analysed on a $1 \%$ agarose gel containing ethidium bromide.

\section{Reverse transcriptase polymerase chain reaction}

cDNA was synthesised with the use of avian myeloma virus reverse transcriptase (RT; Promega, Madison, Wisconsin, USA). Primers were annealed by cooling down from $70^{\circ} \mathrm{C}$ to room temperature. cDNA was synthesised by incubation of the mRNA for 30 minutes at $42^{\circ} \mathrm{C}$. Polymerase chain reactions (PCRs) (total volume of $25 \mu \mathrm{l}$ ) contained $1 \mu \mathrm{l}$ of the cDNA solution, $1 \times$ PCR core buffer (Promega), $2 \mathrm{mM}$ magnesium 

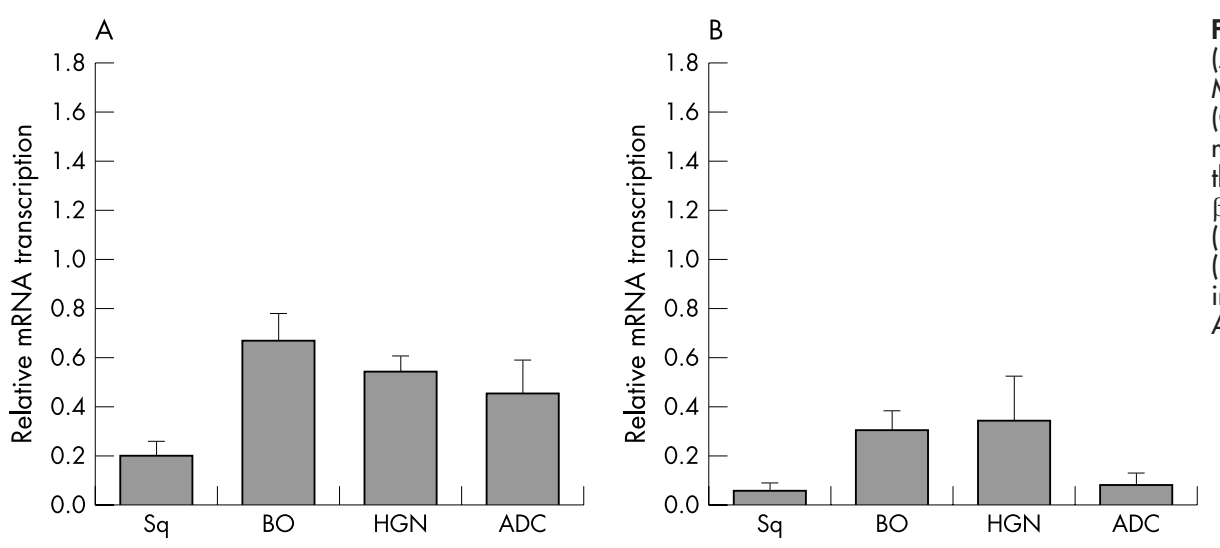

Figure 2 Mean relative expression of (A) MUC1, (B) MUC2, (C) MUC3, (D) MUC4, (E) MUC5AC, (F) MUC5B, and (G) MUC6. The measurement of mucin mRNA was performed by normalising the band area and intensity with that of $\beta$ actin. Sq, squamous epithelium ( $\mathrm{n}=32$ ); BO, Barrett's oesophagus ( $\mathrm{n}=30$ ); HGN, high grade intraepithelial neoplasia ( $\mathrm{n}=6$ ); and $A D C$, adenocarcinoma ( $n=15)$.
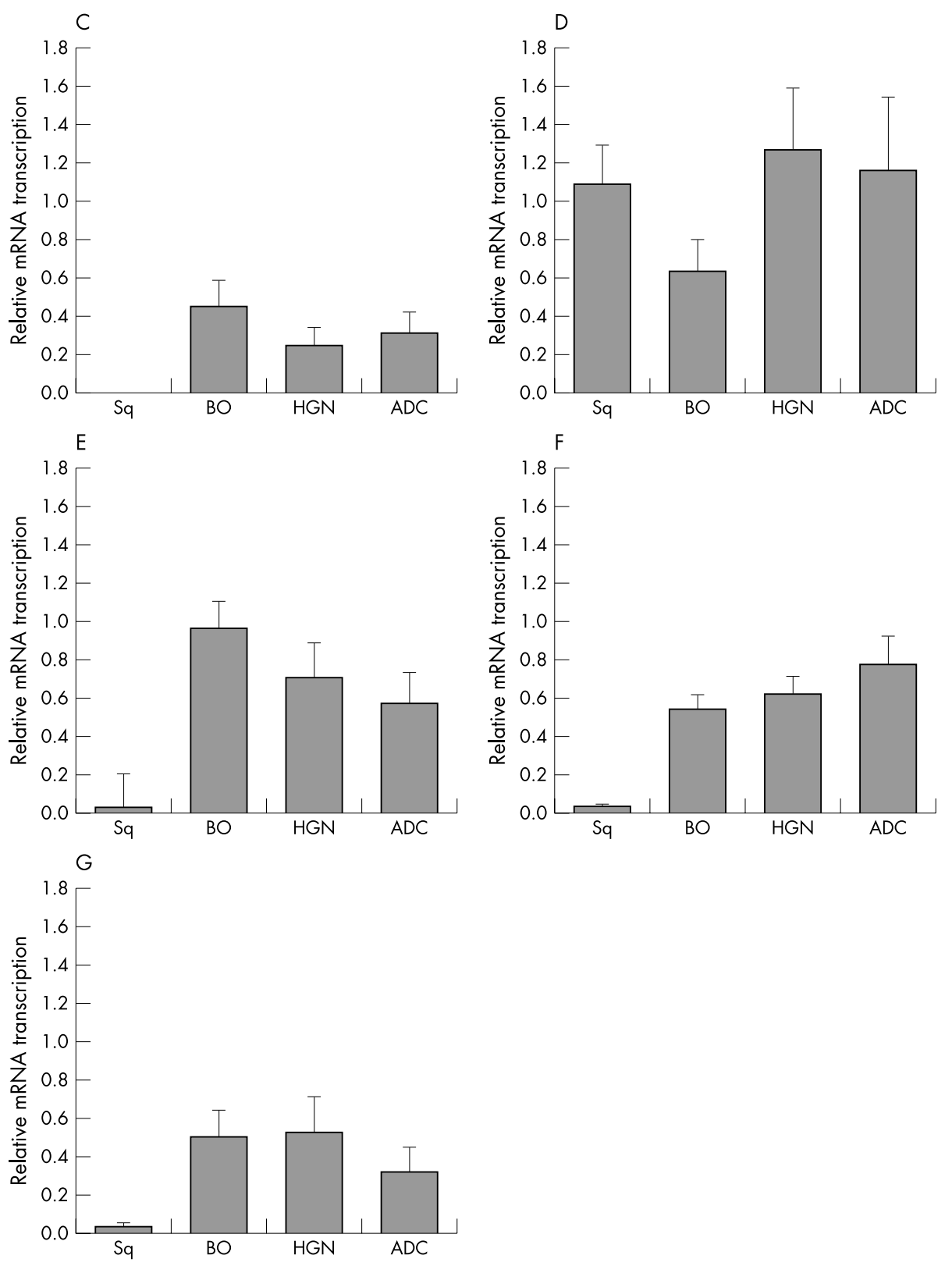

chloride, $0.4 \mu \mathrm{M}$ forward and reverse primer, $200 \mu \mathrm{M}$ of each nucleotide (Promega), and $0.02 \mathrm{U} / \mu \mathrm{l}$ Taq polymerase (Promega). PCR conditions were 35 cycles at $94^{\circ} \mathrm{C}$ for 30 seconds, $55^{\circ} \mathrm{C}$ for 30 seconds, and $72^{\circ} \mathrm{C}$ for one minute. PCR products were visualised on a $1 \%$ agarose gel and stained with ethidium bromide. Band size and intensity were measured with Kodak ID software (Kodak, Rochester, Minnesota, USA) version 3.5 by normalising against the 
housekeeping gene $\beta$ actin, as described previously. ${ }^{17}$ Table 1 lists the primers used.

\section{Protein crossblot}

Aliquots of $20 \mu \mathrm{g}$ of protein were loaded in the lanes of a reverse line blotter (Immunetics, Cambridge, UK) on a PVDS membrane (Roche, Mannheim, Germany). After one hour of incubation at room temperature the samples were removed and the membrane was blocked with 5\% Protifar non-fat milk (Nutricia, Cuijk, the Netherlands) in phosphate buffered saline containing $0.1 \%$ Tween. The primary antibodies antiMUC2 (clone Ccp58; Novocastra, Newcastle, UK), antiMUC5AC (clone 45Ml; Zymed, San Francisco, California, USA), and anti-MUC6 (clone CLH5; Novocastra) were loaded at an angle of $90^{\circ}$ on to the protein samples. An alkaline phosphatase labelled goat anti-mouse IgG antibody (Southern Biotech Associates, Birmingham, Alabama, USA) was used as conjugate and $0.18 \mathrm{mg} / \mathrm{ml}$ 5-bromo-4-dichloro3-indolyl phosphate (BCIP; Promega) and $0.35 \mathrm{mg} / \mathrm{ml}$ nitroblue tetrazolium (NBT; Promega) in $0.1 \mathrm{M}$ Tris/HCl $(\mathrm{pH} 9.5), 0.1 \mathrm{M} \mathrm{NaCl}$, and $5 \mathrm{mM} \mathrm{MgCl}_{2}$ were added as substrate. Immunohistochemical staining of gastric antrum and colonic mucosa confirmed that the primary antibodies detected the mature mucin protein in the case of MUC5AC and MUC6, or a precursor peptide, in the case of MUC2.

\section{Statistical analyses}

RT-PCR data are presented as mean (SEM). Statistical analyses were performed with the Mann-Whitney U test. A $\mathrm{p}$ value $<0.05$ was considered significant.

\section{RESULTS}

\section{Mucin mRNA}

Figure 1 shows the results of RT-PCR testing of different mucins in squamous epithelium, BO, HGN, and ADC. Figure 2 shows the mean transcription levels of individual mucins relative to the transcription of $\beta$ actin in the same sample. Overall, mucin transcription was low or absent in squamous epithelium (relative transcription level, $<0.2$ ), except for MUC4 (relative transcription level, 1.1). Compared with squamous epithelium, MUC4 was downregulated in BO (relative transcription level, $0.62 ; \mathrm{p}=0.01$ ), whereas the other mucins tested were considerably upregulated in $\mathrm{BO}$ (relative transcription level, $>0.4 ; \mathrm{p}<0.001$ ). In HGN, mucin transcription levels were similar to those seen in $\mathrm{BO}$, except for MUC4, which was significantly higher in HGN than in BO (relative transcription levels $1.27 v 0.62$; $\mathrm{p}=0.037)$. In most adenocarcinomas, the mucin mRNA

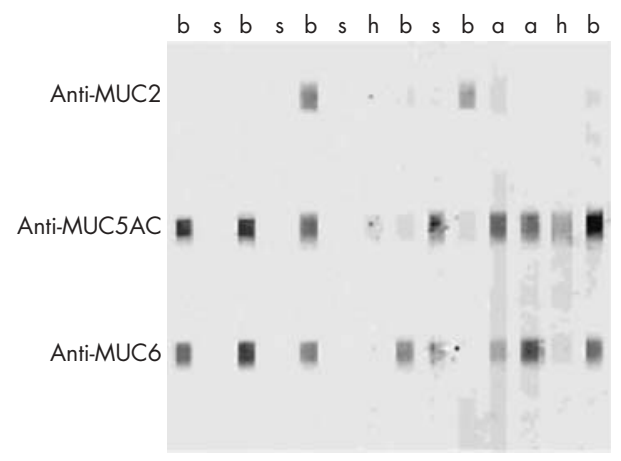

Figure 3 Representative example of protein crossblot. Protein samples were spotted in lanes on a membrane. Primary antibodies were spotted in lanes at an angle of $90^{\circ}$ and were detected with an alkaline phosphatase labelled secondary antibody. s, squamous epithelium; b, Barrett's oesophagus; $h$, high grade intraepithelial neoplasia; $a$, adenocarcinoma. expression was lower than in $\mathrm{BO}$ without intraepithelial neoplasia or with HGN. Amplification of residual chromosomal DNA was not found. Sequencing and comparison with previous published sequences confirmed the correct nature of the mucin PCR products.

\section{Mucin protein expression}

Protein fractions from the same biopsies as the mRNA fractions were analysed by protein crossblot to determine the mucin patterns at the protein level (fig 3). Commercial antibodies that recognise the denatured antigen were only available for MUC2, MUC5AC, and MUC6. Crossblot analysis revealed that in squamous epithelium MUC2 expression was present in two of 32 patients, for MUC5AC in nine of 32 patients, and for MUC6 in two of 32 patients. In the BO samples, MUC2 was expressed in 17 of 30 patients, MUC5AC in 28 of 30 patients, and MUC6 in 26 of 30 patients. In HGN, MUC6 was expressed in 15 of 30 samples, whereas expression of MUC2 and MUC5AC was comparable to that seen in BO (three of six and six of six, respectively). MUC5AC and MUC6 protein were found in nine of 15 and MUC2 protein in three of 15 of the ADC samples (fig 4). Protein data were found to correlate with the mRNA data.

\section{Correlation between $\mathrm{Bax}$ and $\mathrm{Bcl}-2$ mRNA and mucin mRNA expression}

The correlation between mucin mRNA expression and the apoptosis markers Bax and Bcl-2 was determined by calculating the ratio of proapoptotic Bax and antiapoptotic Bcl-2 mRNA. The amounts of Bax and Bcl-2 mRNA were determined by semiquantitative RT-PCR (fig 5). The Bax : Bcl-2 ratio was increased in HGN compared with $\mathrm{BO}$ (ratio $1.71 \vee 0.83 ; \mathrm{p}=0.04$ ). In $\mathrm{ADC}$, the ratio was lower than in HGN (0.95), but this difference was not significant $(\mathrm{p}=0.22)$. The raised $\mathrm{Bax}: \mathrm{Bcl}-2$ ratio in $\mathrm{HGN}$ was associated with an increase in MUC4 mRNA.

\section{DISCUSSION}

Changes in the expression pattern of mucins have been associated with the development of early carcinomas of the colon, gallbladder, and the respiratory tract. ${ }^{18-21}$ The expression pattern of mucins in oesophageal adenocarcinoma has also been determined ${ }^{10}{ }_{11}^{22}$; however, the pattern of mucin expression in high grade intraepithelial neoplasia, the lesion that precedes infiltrating adenocarcinoma, has not been clarified. In our study, the transcription and expression of various mucins in biopsies of oesophageal squamous epithelium, BO, HGN, and ADC were determined. From each biopsy sample, both RNA and protein were purified, thus minimising sample discordance between RNA and protein analysis. Most mucins were upregulated in $\mathrm{BO}$ compared with squamous epithelium. In adenocarcinomas, a greater variety, with a trend towards lower mucin expression compared with $\mathrm{BO}$, was seen. Compared with non-dysplastic BO, HGN contained higher amounts of MUC4 mRNA.

High expression of the secreted mucins MUC2, MUC5AC, MUC5B, and MUC6 has been reported previously in $\mathrm{BO}^{10}{ }^{12}$ as has their downregulation in adenocarcinoma of the oesophagus. ${ }^{10}{ }^{11}$ In contrast to these reports, low amounts of these mucins were found in some squamous epithelial samples. Because RT-PCR is a very sensitive technique, these low amounts could have escaped detection in immunohistochemical studies.

However, the possibility that the squamous samples were contaminated with intestinal glands or subepithelial proper glands cannot be excluded. Adjacent biopsies were analysed for the purity of the epithelium because approaches designed for the extraction of mRNA from fixed tissue used for histological analysis have not been validated for the 

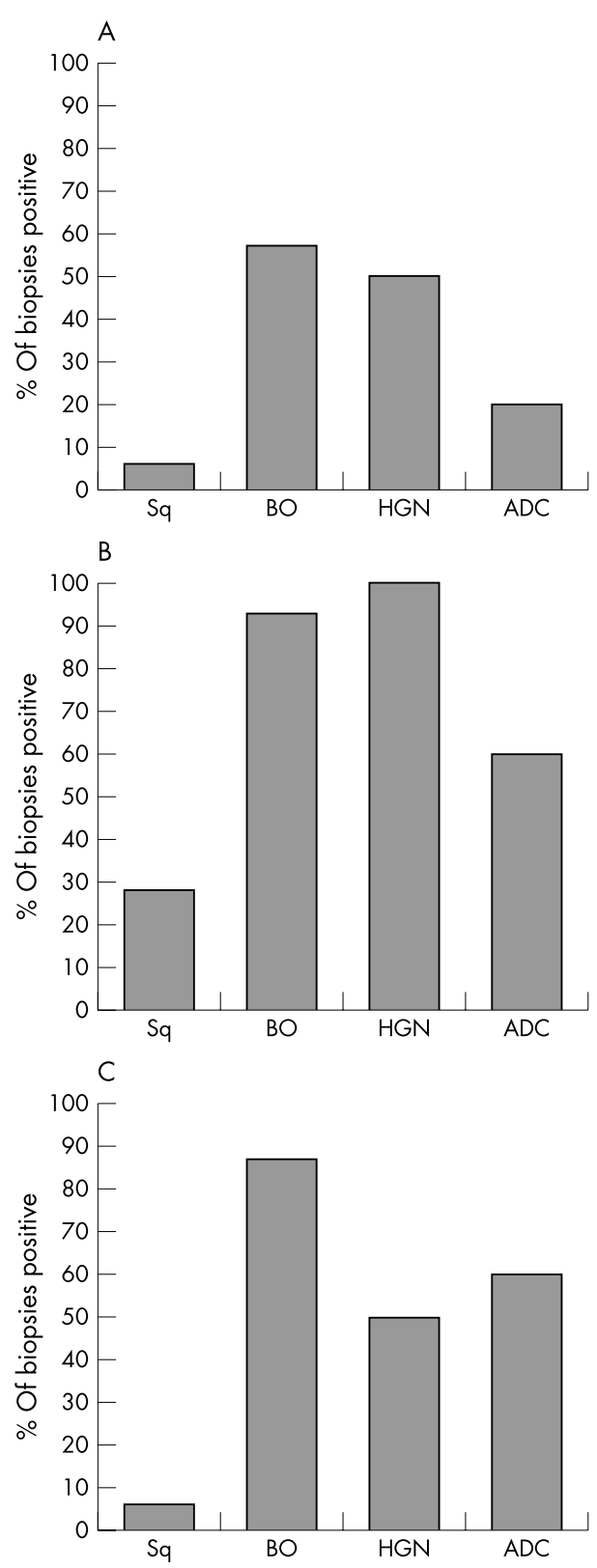

Figure 4 Protein crossblot analysis: percentage of samples positive for (A) MUC2, (B) MUC5AC, and (C) MUC6. Sq, squamous epithelium $(\mathrm{n}=32) ; \mathrm{BO}$, Barrett's oesophagus $(\mathrm{n}=30$ ); $\mathrm{HGN}$, high grade intraepithelial neoplasia $(n=6)$; and $A D C$, adenocarcinoma $(n=15)$.

quantitative comparison of mRNA. Furthermore, the presence of the MUC2, MUC5AC, and MUC6 proteins in the squamous epithelium could have been caused by reflux of gastric mucous components, including these mucins.

Most reports describe high expression of MUCl in squamous epithelium and low expression in $\mathrm{BO},{ }^{10}{ }^{11} 23$ whereas the opposite is shown in our present study. An explanation for this could be that most studies used unrelated squamous epithelium samples, whereas in our study paired squamous/BO samples from a single patient were used in which inflammation could have altered the mucin pattern. However, the most striking result is the upregulation of MUC4 in HGN compared with BO without intraepithelial neoplasia. This has not been reported before.

Duodenogastro-oesophageal reflux has been implicated in the development of $\mathrm{BO}$ and oesophageal adenocarcinoma. ${ }^{24}$

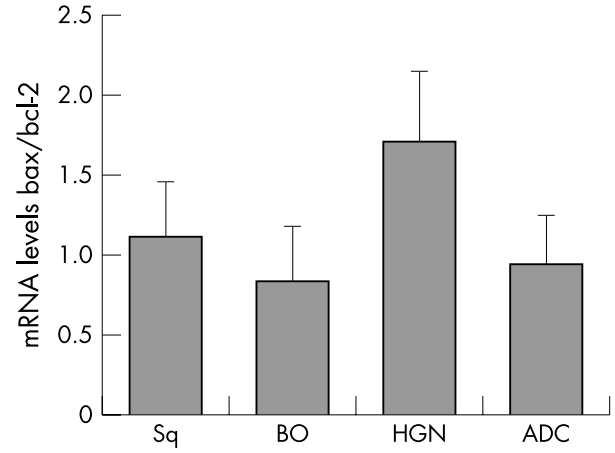

Figure 5 Summary of the data on $\mathrm{Bax}: \mathrm{Bcl}-2$ ratios. The measurement of $\mathrm{Bax}$ and $\mathrm{BCl}-2$ mRNA was performed by dividing the band area and intensity of Bax by that of $B c l-2$. Sq, squamous epithelium $(n=9) ; B O$, Barrett's oesophagus ( $n=8)$; HGN, high grade intraepithelial neoplasia $(\mathrm{n}=6)$; and $\mathrm{ADC}$, adenocarcinoma $(\mathrm{n}=4)$.

Recently, it was found that in particular bile salts and their conjugates induce the transcription of MUC4 mRNA in oesophageal cancer cells. ${ }^{25}$ This could explain the observed increase of MUC4 in HGN.

"The most striking result is the upregulation of MUC4 in high grade intraepithelial neoplasia compared with Barrett's oesophagus without intraepithelial neoplasia"

Increased MUC4 expression has also been found in other early neoplastic lesions, such as early pancreatic carcinomas and dysplastic cervical lesions. ${ }^{26}{ }^{27}$ When produced in normal quantities, MUC4 has been reported to function as a steric barrier that limits the access of other cells and large molecules to the epithelium, thereby protecting it from damage. ${ }^{28}$ In contrast, overexpression of MUC4 disrupts cellcell and cell-matrix interactions, which could initiate the dissociation of tumour cells from the primary tumour. ${ }^{29}$ Finally, overexpression of MUC4 may result in the masking of tumour antigens, thereby effectively suppressing tumour cell killing by cytotoxic lymphocytes.$^{28}$ Because oesophageal adenocarcinoma often metastasises at an early phase, loss of cell adhesion probably occurs at an early stage of carcinogenesis. Increased MUC4 expression could contribute to the detachment of tumour cells from the primary adenocarcinoma.

MUC4 protein also acts as a ligand for the receptor tyrosine kinase, Erb-B2, a protooncogene that is abnormally expressed in the membranes of Barrett's epithelium and associated adenocarcinoma. ${ }^{30}{ }^{31}$ The MUC4-Erb-B2 complex is involved in the inhibition of apoptosis, ${ }^{32}$ thereby promoting tumour growth. Strong suppression of apoptosis was seen in MUC4 overexpressing tumours in mice. ${ }^{16}$ In our study, the mRNA levels of the apoptosis markers Bax and Bcl-2 were also determined. Inhibition of apoptosis was not found in the HGN samples with increased MUC4 expression. In contrast, the Bax : Bcl-2 ratio was increased in HGN compared with BO. This might indicate that MUC4 plays only a minor role in the regulation of apoptosis in HGN in humans.

An increased apoptotic rate does not fit in with the model of neoplastic progression. ${ }^{33}$ However, reduced Bcl-2 expression during the neoplastic progression of $\mathrm{BO}$ has been reported before. ${ }^{34}$ A recent report described clear Bax and Bcl-2 expression in both BO, HGN, and ADC, but results were not quantitative. ${ }^{35}$ Other apoptotic proteins, such as the Fas ligand and caspases, may have an antiapoptotic effect in BO with HGN, to compensate for the proapoptotic Bax : Bcl-2 balance. 


\section{Take home messages}

- Mucin expression varies during the development of oesophageal adenocarcinoma in Barrett's oesophagus (BO)

- Membrane bound mucin MUC4 is associated with the development of high grade intraepithelial neoplasia in $\mathrm{BO}$ and could serve as an early tumour marker in this process, although additional studies are necessary to verify this hypothesis

- In contrast to animal studies, upregulation of MUC4 in high grade intraepithelial neoplasia is associated with increased apoptosis, suggesting that MUC4 plays a minor role in the regulation of apoptosis in $\mathrm{BO}$

In conclusion, the results of our study show that mucin expression is altered in BO. Membrane bound mucin MUC4 is associated with the development of high grade intraepithelial neoplasia in $\mathrm{BO}$, but not with a decrease in apoptosis. This suggests a role for MUC4 as an early tumour marker in BO. In combination with other tumour markers, it could facilitate the early diagnosis of adenocarcinoma both in vitro and in vivo. However, additional studies are necessary to verify this hypothesis.

\section{ACKNOWLEDGEMENTS}

The authors acknowledge L Moons, A van Vliet, J Kwekkeboom, and J Dekker for helpful and stimulating discussions during the preparation of the manuscript.

\section{Authors' affiliations}

D A Bax, J Haringsma, P D Siersema, E J Kuipers, J G Kusters, Department of Gastroenterology and Hepatology, Erasmus MC University Medical Centre, 3015 GD Rotterdam, The Netherlands A W C Einerhand, Laboratory of Paediatrics, Erasmus MC - Sophia Children's Hospital, Rotterdam, The Netherlands

H van Dekken, Department of Pathology, Erasmus MC - University Medical Centre, Rotterdam, The Netherlands

P Blok, Department of Pathology, Leyenburg Ziekenhuis, The Hague, The Netherlands

\section{REFERENCES}

1 Avidan B, Sonnenberg A, Schnell TG, et al. Hiatal hernia size, Barrett's length, and severity of acid reflux are all risk factors for esophageal adenocarcinoma. Am J Gastroenterol 2002;97:1930-6.

2 Lagergren J, Bergstrom R, Lindgren A, et al. Symptomatic gastroesophageal reflux as a risk factor for esophageal adenocarcinoma. N Engl J Med 1999;340:825-31.

3 Hamilton SR, Smith RR. The relationship between columnar epithelial dysplasia and invasive adenocarcinoma arising in Barrett's esophagus. Am J Clin Pathol 1987;87:301-12.

4 Falk GW. Barrett's esophagus. Gastroenterology 2002;122:1569-91.

5 Sampliner RE. Practice guidelines on the diagnosis, surveillance, and therapy of Barrett's esophagus. The practice parameters committee of the American College of Gastroenterology. Am J Gastroenterol 1998;93:1028-32.

6 Craanen ME, Blok P, Meijer GA, et al. Surveillance in Barrett's oesophagus: a critical reappraisal. Scand J Gastroenterol Suppl 2002;236:4-8.

7 Falk GW, Rice TW, Goldblum JR, et al. Jumbo biopsy forceps protocol still misses unsuspected cancer in Barrett's esophagus with high-grade dysplasia. Gastrointest Endosc 1999;49:170-6.

8 Reid BJ, Haggitt RC, Rubin CE, et al. Observer variation in the diagnosis of dysplasia in Barrett's esophagus. Hum Pathol 1988;19:166-78.

9 Corfield AP, Carroll D, Myerscough N, et al. Mucins in the gastrointestinal tract in health and disease. Front Biosci $2001 ; 6:$ D1321-57.
10 Arul GS, Moorghen M, Myerscough N, et al. Mucin gene expression in Barrett's oesophagus: an in situ hybridisation and immunohistochemical study. Gut 2000;47:753-61.

11 Guillem P, Billeret V, Buisine MP, et al. Mucin gene expression and cell differentiation in human normal, premalignant and malignant esophagus. Int J Cancer 2000;88:856-61

12 Labouvie C, Machado JC, Carneiro F, et al. Differential expression of mucins and trefoil peptides in native epithelium, Barrett's metaplasia and squamous cell carcinoma of the oesophagus. J Cancer Res Clin Oncol 1999;125:71-6.

13 Komatsu M, Carraway CA, Fregien NL, et al. Reversible disruption of cellmatrix and cell-cell interactions by overexpression of sialomucin complex. J Biol Chem 1997;272:33245-54.

14 Wesseling J, van der Valk SW, Vos HL, et al. Episialin (MUC1) overexpression inhibits integrin-mediated cell adhesion to extracellular matrix components. J Cell Biol 1995; 129:255-65.

15 Jepson S, Komatsu M, Haq B, et al. Muc4/sialomucin complex, the intramembrane ErbB2 ligand, induces specific phosphorylation of ErbB2 and enhances expression of p27(kip), but does not activate mitogen-activated kinase or protein kinaseB/Akt pathways. Oncogene 2002;21:7524-32.

16 Komatsu M, Jepson S, Arango ME, et al. Muc4/sialomucin complex, an intramembrane modulator of ErbB2/HER2/Neu, potentiates primary tumor growth and suppresses apoptosis in a xenotransplanted tumor. Oncogene 2001;20:461-70.

17 Andrianifahanana M, Moniaux N, Schmied BM, et al. Mucin (MUC) gene expression in human pancreatic adenocarcinoma and chronic pancreatitis: a potential role of MUC4 as a tumor marker of diagnostic significance. Clin Cancer Res 2001;7:4033-40.

18 Bartman AE, Sanderson SJ, Ewing SL, et al. Aberrant expression of MUC5AC and MUC6 gastric mucin genes in colorectal polyps. Int J Cancer 1999;80:210-18

19 Inaba T, Sano H, Kawahito Y, et al. Induction of cyclooxygenase-2 in monocyte/macrophage by mucins secreted from colon cancer cells. Proc Natl Acad Sci U S A 2003;100:2736-41.

20 Copin MC, Devisme L, Buisine MP, et al. From normal respiratory mucosa to epidermoid carcinoma: expression of human mucin genes. Int J Cancer 2000;86: 162-8.

21 Sasaki M, Yamato T, Nakanuma Y, et al. Expression of MUC2, MUC5AC and MUC6 apomucins in carcinoma, dysplasia and non-dysplastic epithelia of the gallbladder. Pathol Int 1999;49:38-44.

22 Warson C, Van De Bovenkamp JH, Korteland-Van Male AM, et al. Barrett's esophagus is characterized by expression of gastric-type mucins (MUC5AC, MUC6) and TFF peptides (TFF1 and TFF2), but the risk of carcinoma development may be indicated by the intestinal-type mucin, MUC2. Hum Pathol 2002;33:660-8.

23 Chinyama CN, Marshall RE, Owen WJ, et al. Expression of MUC1 and MUC2 mucin gene products in Barrett's metaplasia, dysplasia and adenocarcinoma: an immunopathological study with clinical correlation. Histopathology 1999;35:517-24.

24 Miwa K, Sahara H, Segawa M, et al. Reflux of duodenal or gastro-duodenal contents induces esophageal carcinoma in rats. Int $J$ Cancer 1996:67:269-74

25 Mariette $C$, Perrais $M$, Leteurtre $E$, et al. Transcriptional regulation of human mucin MUC 4 by bile acids in oesophagus cancer cells is promoter dependent and involves activation of phosphatidylinositol 3-kinase signalling pathway. Biochem J 2004;377:701-8.

26 Lopez-Ferrer A, Alameda F, Barranco C, et al. MUC4 expression is increased in dysplastic cervical disorders. Hum Pathol 2001;32:1197-202.

27 Swartz MJ, Batra SK, Varshney GC, et al. MUC4 expression increases progressively in pancreatic intraepithelial neoplasia. Am J Clin Pathol 2002;117:791-6.

28 Komatsu M, Yee L, Carraway KL. Overexpression of sialomucin complex, a rat homologue of MUC4, inhibits tumor killing by lymphokine-activated killer cells. Cancer Res 1999;59:2229-36.

29 Komatsu M, Tatum L, Altman NH, et al. Potentiation of metastasis by cell surface sialomucin complex (rat MUC4), a multifunctional anti-adhesive glycoprotein. Int J Cancer 2000;87:480-6.

30 Walch A, Specht K, Bink K, et al. Her-2/neu gene amplification, elevated mRNA expression, and protein overexpression in the metaplasia-dysplasiaadenocarcinoma sequence of Barrett's esophagus. Lab Invest 2001;81:791-801.

31 Jankowski J, Coghill G, Hopwood D, et al. Oncogenes and onco-suppressor gene in adenocarcinoma of the oesophagus. Gut 1992;33:1033-8.

32 Carraway KL, Perez A, Idris N, et al. Muc4/sialomucin complex, the intramembrane ErbB2 ligand, in cancer and epithelia: to protect and to survive. Prog Nucleic Acid Res Mol Biol 2002;71:149-85.

33 Hanahan D, Weinberg RA. The hallmarks of cancer. Cell 2000;100:57-70.

34 Raouf AA, Evoy DA, Carton E, et al. Loss of Bcl-2 expression in Barrett's dysplasia and adenocarcinoma is associated with tumor progression and worse survival but not with response to neoadiuvant chemoradiation. Dis Esophagus 2003;16:17-23.

35 van der Woude CJ, Jansen PL, Tiebosch AT, et al. Expression of apoptosisrelated proteins in Barrett's metaplasia-dysplasia-carcinoma sequence: a switch to a more resistant phenotype. Hum Pathol 2002;33:686-92. 